
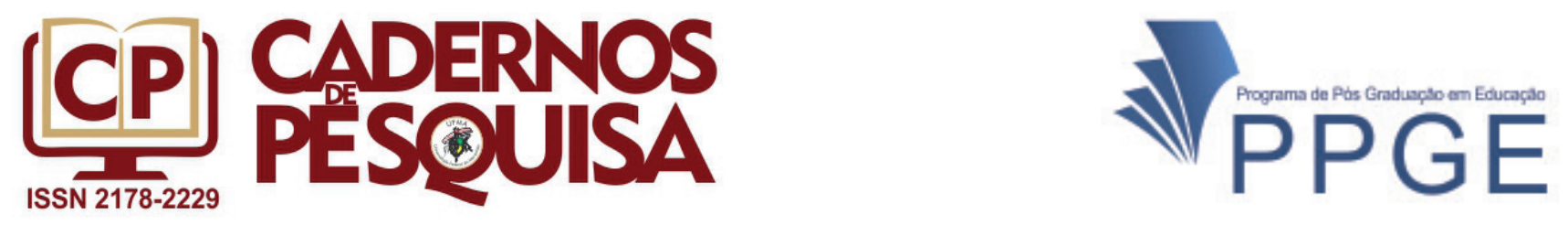

\title{
ORIGENS DOS CONFLITOS NA ESCOLA NA PERSPECTIVA DE UMA COMUNIDADE ESCOLAR
}

\author{
ORIGINS OF CONFLICTS AT SCHOOL FROM THE \\ PERSPECTIVE OF SCHOOL COMMUNITY
}

\section{ORÍGENES DE LOS CONFLICTOS EN LA ESCUELA EN LA PERSPECTIVA DE UNA COMUNIDAD ESCOLAR}

\author{
Ernesto Barros André \\ http://orcid.org/0000-0002-6948-212X
}

Anabel Moriña

http://orcid.org/0000-0002-0852-7523

\begin{abstract}
Resumo: Esta investigação escrutina as origens dos conflitos numa comunidade escolar de contexto angolano. Com base nos objectivos fixados, recorreu-se à metodologia qualitativa, tendo sido utilizadas entrevistas grupais semi-estruturadas, com a participação de 167 elementos dentre professores, alunos e familiares, cujos dados foram analisados através do método de análise de conteúdo assistido pelo Maxqda 12. A pesquisa revela que os conflitos mais relevantes naquela comunidade escolar relacionam-se com o não respeito das normas ético-deontológicas por parte dos docentes, com a indisciplina e má educação familiar dos alunos e com o não acompanhamento dos alunos por parte dos seus pais e encarregados da educação.
\end{abstract}

Palavras-chave: Conflitos; origem dos conflitos; comunidade escolar.

\begin{abstract}
This research monitors the origins of conflicts in a school community of Angolan context. Based on the objectives set, resorted to the qualitative methodology, having been used semi-structured interviews group, with the participation of 167 elements among teachers, students and their families, whose data were analyzed using the method content analysis assisted by Maxqda 12. The survey reveals that the most significant conflicts that school community relate to non-compliance with ethical conduct on the part of teachers, with the indiscipline and bad family education of students and with no monitoring of students by part of their parents.
\end{abstract}

Keywords: Conflicts; origin of the conflict; school community.

Resumen: Esta investigación escudriña los orígenes de los conflictos en una comunidad escolar de contexto angoleño. Con base en los objetivos fijados, se recurrió a la metodologia cualitativa, habiendo sido utilizadas entrevistas grupales semiestructuradas, com la participación de 167 elementos entre profesores, alumnos y familiares, cuyos datos fueron analizados a través del método de análisis de contenido asistido por el Maxqda 12.La investigación revela que los conflictos más relevantes en aquella comunidad escolar se relacionan 
con el no respeto de las normas ético-deontológicas por parte de los docentes, con la indisciplina y mala educación familiar de los alumnos y con el no acompañamiento de los alumnos por parte de sus padres y los encargados de la educación.

Palabras clave: Conflictos; origen de los conflictos; comunidad escolar.

\section{INTRODUÇÃO}

Nada mais é interessante que de conhecer a origem de um dilema para se encontrar caminhos de trilhar com ele. No caso dos conflitos, não sabendo lidar com eles para produção dos aspectos positivos que possam ser aproveitados na dinamização dos grupos, torna-se imprescindível conhecer a fonte para estancar os efeitos negativos decorrentes dessas situações. Nas suas diversas formas, eles são presentes na existência humana e provêem de muitas situações que podem ser intrínsecas ou extrínsecas ao indivíduo ou grupo de indivíduos cujas fontes principais numa comunidade escolar tal como definiu a Saiti (2014) implicam questões interpessoais e organizacionais.

Apesar da existência de regras de convivência entre indivíduos e o aspecto organizacional regulamentado, os atropelos à regulamentação, conjugado com o aspecto de liberdade do homem, nascem os conflitos. Ainda nos grupos, a interacção entre indivíduos, a hierarquização dos órgãos e o posicionamento dos elementos, tem produzido os conflitos que podemos chamar de conflitos de status (BENDERSKY \& HAYS, 2017) cujas razões e efeitos de contingência permanecem não claras (LEE, CHOI \& KIM, 2018).

A literatura existente retrata o conflito intragrupo nos aspectos produtivos, relacionais e nas implicações criativas do grupo (GROYSBERG, POLZER, \& ELFENBEIN, 2011; PETIT, SAUER, \& LOUNT, 2014; PETIT, DOYLE, \& LOUNT, 2016). As ideias criativas dos membros do grupo devem ser partilhadas para a promoção da criatividade, no entanto o conflito de estatuto inibe essas ideias e torna-se um grande problema na promoção da criatividade da equipa de trabalho (CHEN, MADILVA, CAMPBELL-BUSH, WU, \& WU, 2013). A luta pelo status tornou-se mais relevante na vida humana (CHENG, TRACY, \& HENRICH, 2010) com considerações evolutivas na vida social (CHENG et al., 2010).

Apesar da comunidade escolar formar um todo com as suas implicações e diferenças culturais e de interesse, ainda existem subgrupos com os mesmos problemas de diferenciação, de interesse e de hierarquização social producentes de conflitos na sua interacção. Considera-se que para além dos conflitos intragrupos ainda reservam-se os conflitos intergrupos ( LU, FUNG, DOOSJE, 2017) na defesa dos interesses dos diferentes grupos ou subgrupos, na importância de cada subgrupo em relação ao outro na comunidade, mesmo tendo em comum os mesmos objectivos com vias diferentes de alcançá-los.

Por ser uma questão inerente à vida do próprio homem, o tema sobre os conflitos é muito abordado em todas esferas da convivência humana. Nas escolas o que mais atrai os investigadores, prende-se com a violência e o bullyng ( HOJBOTA et al., 2014; HYMEL, \& SWEARER, 2015; KOH, \& WONG, 2017) dos alunos, a indisciplina e outros comportamentos indecorosos na sala de aula (BAGNALL, \& NAKAR, 2017; DUARTE, ESCARIO, \& 
SANAGUSTíN, 2017; SERVOSS, 2017), as causas e o impacto dos conflitos nas escolas (OMISORE, \& ABIODUN, 2014; VASQUEZ-SALGADA, GRENFIELD, \& BURGOS-CIENFUEGOS, 2015; GOKSOY, \& ARGON, 2016; NAIRZ-WIRTH, \& FELDMAN, 2017; OZGAN, 2016), as estratégias de gestão e de resolução dos conflitos escolares (SAITI, 2014;SHAHMOHAMMADI, 2014; TITREK, MARAL, \& KIZULKAYA, 2015; CARTON, 2016; DOGAN, 2016; WHITESIDE, 2016).

Tratando-se de estudos inerentes à vida social humana, com nível do desenvolvimento cultural de Angola, trabalhos relacionados ao comportamento e atitudes belicosas encontrariam respaldo no nosso mosaico literário com uma base de dados garantida sobre os conflitos escolares. Todavia, nessa matéria e noutras de suma importância, nada se faz sentir. Iniciativas do género, despertam o interesse em trabalhar nos domínios da ciência para se alcançar uma análise profunda da situação em destaque e receber de outras pessoas várias contribuições que nos ajudariam a desenvolver a ciência no nosso contexto.

As causas dos conflitos no ambiente escolar são bem conhecidas a julgar pela importância da literatura nessa matéria nos países com cultura científica desenvolvida. No entanto, as causas das causas que podemos considerar como fontes donde emanam as causas, em certos contextos, como o nosso, não são divulgados, suponho, por inexistência de pesquisas. Daí, o propósito de contribuir para um levantamento criterioso da origem dos conflitos escolares naquele estabelecimento de ensino, sem se esquecer de debelar algumas situações e os tipos de conflitos produzidos no sentido de irmos relacionando este surgimento de desavenças numa comunidade onde tudo se quer harmónico. Ou ainda, conhecendo as fontes principais dessas situações, facilmente uma proposta de gestão pode ser desencadeada para se alcançar êxitos, aproveitando os aspectos positivos dos conflitos para dinamizar a comunidade escolar.

\section{MÉTODO}

A nossa investigação tem como palco de realização uma escola secundária do I ciclo de contexto angolano, situado num dos Município do interior da Província de Cabinda, em referência o Buco-Zau. A mesma tem como finalidade de escrutinar a origem da realidade de uma situação educacional vivida todos os anos lectivos.

\section{OBJECTIVO E QUESTÕES DE INVESTIGAÇÃO}

As situações decorrentes a nível escolar são de particular interesse dos investigadores da educação. $O$ ambiente escolar é digno de produzir as condições favoráveis para o processo docente-educativo todavia, sobressaem também as situações que influem negativamente sobre a produção dos saberes nas crianças. Desta feita, é de nosso interesse, desvendar a origem das situações conflituosas naquele estabelecimento de ensino partindo de três questões essenciais da pesquisa:

- Quais são as situações identificadas como produtoras de conflitos naquela comunidade escolar? 
- Que tipos de conflitos são produzidos?

- Quais são as origens das situações conflituosas na escola em referência?

\section{PARTICIPANTES}

A nossa amostra intencional, seleccionada a partir de um questionário, se reagrupa em três subamostras representando os três subgrupos essenciais da comunidade escolar do centro em estudo, sendo professores alunos e familiares.

Dos 167 elementos seleccionados, constituiu-se 24 grupos, sendo 8 grupos por cada subgrupo da comunidade escolar.

\section{INSTRUMENTOS DE RECOLHE DE DADOS}

As técnicas aplicadas neste estudo consistem na realização dos guiões de entrevistas semi-estruturadas para os três subgrupos a fim de uma análise profunda das situações conflituais vividas na escola entre professores, alunos e familiares, com a tipificação e escrutínio da origem das mesmas.

Uma vez elaborados, os guiões foram submetidos à apreciação e aprovação dos espertos das áreas de pedagogia, sociologia e psicologia.

\section{ANÁLISE DE DADOS}

O sistema de categorias estabelecido, tal como proposto por Miles e Humberman (1994), é um instrumento que nos permitiu analisar estruturalmente as diferentes respostas, classificá-las e codificá-las para a obtenção da informação precisa. Este sistema foi assistido pelo programa MAXQDA, versão 12.

Os códigos estabelecidos no sistema, foram reagrupados em 3 categorias, a saber:

- Situações de conflitos;

- Tipos de conflitos;

- Origens dos conflitos.

\section{RESULTADOS}

Consoante as categorias obtidas, os resultados que aqui apresentamos se situam em três eixos principais consubstanciados na apreensão dos conflitos, na tipificação dos mesmos e no estabelecimento da origem dessas situações tal como revelado pela comunidade escolar.

\section{SITUAÇÕES DE CONFLITOS}

Dos numerosos depoimentos sobre as situações identificadas que já produziram os conflitos na escola em estudo entre os professores, os alunos e os pais e encarregados da educação, foram extirpadas as expostas por cada elemento da comunidade, com uma comparação das exposições dos diferentes elementos numa grelha que apresentamos abaixo: 
Familiar 1: "As situações que já levaram conflitos entre encarregados da educação e os professores..., é que os professores nunca consideraram os alunos como seus próprios filhos (...), ele não vai sempre chatear o aluno: faz isso ou vou namorar contigo. Então, quando o aluno está na escola, o professor fica a chatear o aluno: dá-me dinheiro ou vamos na minha casa e vai fazer isto. Tudo isto, o encarregado não vai gostar... Tudo isto cria conflito. Ou com as meninas, o professor que fica como pai na escola mas vai pretender a sua filha..."

Como se verifica no extracto da entrevista com os professores, os mesmos reconhecem a existência desse comportamento não somente naquela escola mas em muitas outras com o agravante de se chegar a gravidezes indesejadas que certamente o docente deverá assumir. E muito desses casos passam despercebidos nos olhos da direcção da escola, quando os familiares consentem resolver o caso com o autor envolvido nessa prática duma maneira sigilosa. O mais agravante ainda é que se verifica casos de pedofilia silenciados, como revela o seguinte extracto:

Professor 31: "Uma das outras situações muito indicadas que pode conduzir os professores em conflitos com os familiares, eh... o facto que tem existido, os professores namorarem com as alunas principalmente esse de menor idade. Isto quando acontece, se não haver acautela, esse professor acaba engravidando a menina. $E$ a aluna se tiver pais e encarregados da educação muito rigorosos, na verdade pode trazer grande conflito. Como já aconteceu em várias escolas."

Muitos casos ou situações de conflitos ressentidas naquela escola, são extraídas e expostas no quadro abaixo. As diferentes situações agrupadas na grelha, foram extraídas nos relatos dos intervenientes que na maioria dos casos, expuseram as mesmas situações:

Tabela 1: Situações de conflitos na escola

\begin{tabular}{|l|l|l|}
\hline \multicolumn{1}{|c|}{ CITADAS PELOS ALUNOS } & CITADAS PELOS FAMILIARES & \multicolumn{1}{c|}{ CITADAS PELOS DOCENTES } \\
\hline - Namoro com as alunas & - Namoro com as alunas & - Namoro com as alunas \\
\hline $\begin{array}{l}\text { - Rivalidade entre aluno e profes- } \\
\text { sor }\end{array}$ & $\begin{array}{l}\text { - Rivalidade entre aluno e profes- } \\
\text { sor }\end{array}$ & $\begin{array}{l}\text { - Rivalidade entre aluno e profes- } \\
\text { sor }\end{array}$ \\
\hline - Pedofilia & - Pedofilia & - Pedofilia \\
\hline - Reprovação por vingança & - Reprovação por vingança & - Reprovação por vingança \\
\hline - Penalizações generalizadas & - Penalizações generalizadas & - Penalizações generalizadas \\
\hline - Desavenças e desacatos & - Desavenças e desacatos & - Desavenças e desacatos \\
\hline $\begin{array}{l}\text { - Falta de humildade nos erros } \\
\text { apontados }\end{array}$ & $\begin{array}{l}\text { - Falta de humildade nos erros } \\
\text { apontados }\end{array}$ & $\begin{array}{l}\text { - Falta de humildade nos erros } \\
\text { apontados }\end{array}$ \\
\hline - Falha na comunicação aos pais & - Falha na comunicação aos pais & - Falha na comunicação aos pais \\
\hline $\begin{array}{l}\text { - Ausências frequentes dos alunos } \\
\text { nas salas de aulas }\end{array}$ & $\begin{array}{l}\text { - Ausências frequentes dos alunos } \\
\text { nas salas de aulas }\end{array}$ & $\begin{array}{l}\text { - Ausências frequentes dos alunos } \\
\text { nas salas de aulas }\end{array}$ \\
\hline $\begin{array}{l}\text { - Comportamento e atitudes } \\
\text { negativas }\end{array}$ & $\begin{array}{l}\text { - Comportamento e atitudes } \\
\text { negativas }\end{array}$ & $\begin{array}{l}\text { - Comportamento e atitudes } \\
\text { negativas }\end{array}$ \\
\hline
\end{tabular}




\begin{tabular}{|l|l|l|}
\hline $\begin{array}{l}\text { - Cumplicidade entre alunos e } \\
\text { professores em práticas desabo- } \\
\text { natórias }\end{array}$ & $\begin{array}{l}\text { - Cumplicidade entre alunos e } \\
\text { professores em práticas desabo- } \\
\text { natórias }\end{array}$ & $\begin{array}{l}\text { - Cumplicidade entre alunos e } \\
\text { professores em práticas desabo- } \\
\text { natórias }\end{array}$ \\
\hline $\begin{array}{l}\text { - Falta de colaboração entre do- } \\
\text { centes e familiares }\end{array}$ & $\begin{array}{l}\text { - Falta de colaboração entre do- } \\
\text { centes e familiares }\end{array}$ & $\begin{array}{l}\text { - Falta de colaboração entre do- } \\
\text { centes e familiares }\end{array}$ \\
\hline - Injustiça & $\begin{array}{l}\text { - Complexo de superioridade e de } \\
\text { inferioridade }\end{array}$ & - Mau comportamento \\
\hline $\begin{array}{l}\text { - Não respeito dos direitos de } \\
\text { outrem }\end{array}$ & $\begin{array}{l}\text { - Utilização do aluno como força } \\
\text { de trabalho caseiro }\end{array}$ & - Educação familiar \\
\hline - Falta de respeito mútuo & $\begin{array}{l}\text { - Desequilíbrio económico entre } \\
\text { professor e aluno }\end{array}$ & - Comunicação deficiente \\
\hline $\begin{array}{l}\text { - Não respeito das normas esta- } \\
\text { belecidas }\end{array}$ & $\begin{array}{l}\text { - Ineficácia na aplicação dos } \\
\text { normativos }\end{array}$ & - Aproveitamento das falhas \\
\hline $\begin{array}{l}\text { - Falta de sigilo profissional dos } \\
\text { professores }\end{array}$ & $\begin{array}{l}\text { - Prestação de intenções por coi- } \\
\text { sas infundadas }\end{array}$ & - O não respeito das normas \\
\hline - Reprovação dos alunos & - Boatos, intrigas e fofocas & - Reprovação dos alunos \\
\hline - Boatos, fofocas e intrigas & - Promessas de reprovação & - Não respeito das hierarquias \\
\hline $\begin{array}{l}\text { - Trabalhos caseiros em benefício } \\
\text { dos professores }\end{array}$ & - Desmoralização & - Ameaças proferidas aos alunos \\
\hline - Assédio sexual & - Desencorajamento & $\begin{array}{l}\text { - Distracção dos alunos na sala } \\
\text { de aulas }\end{array}$ \\
\hline $\begin{array}{l}\text { - Apreciação diferenciada da mes- } \\
\text { ma situação }\end{array}$ & - Falta de colaboração & Indisciplina e desordem \\
\hline $\begin{array}{l}\text { - A não aplicação das normas } \\
\text { estabelecidas }\end{array}$ & - Falta de consideração & - Mentiras \\
\hline - Falsas promessas & & - Penalizações \\
\hline - Insinuações & - Decisões mal tomadas \\
\hline - Maus tratos & - Ameaças de reprovação \\
\hline - Punições descabidas & $\begin{array}{l}\text { - Adulteração de notas por parte } \\
\text { dos professores nas pautas e } \\
\text { mini-pautas }\end{array}$ \\
\hline
\end{tabular}

Todas essas situações são favorecidas pelas atitudes incorrectas dos membros da comunidade, a saber: a insinuação, a obstinação, a arrogância, a desatenção, o fatalismo, os desafios, os desprezos, a perca do controlo, a desobediência, as atitudes belicosas, etc...

\section{TIPOS DE CONFLITOS}

A partir dos relatos dos membros da comunidade escolar, podemos notar que vários tipos de conflitos se expõem naquele estabelecimento, como se constata nos dois extractos dos encarregados da educação:

Familiar 1: "Tipo de conflitos: (...) Vingança, rancores, ofensas..."

Familiar 16: "Eu dizia que os conflitos que nós podemos encontrar dentro duma instituição... Por exemplo a agressão física, troca de palavras .... 
Não sendo exaustivos nos dois relatos, extraímos em várias entrevistas, o que agrupamos abaixo:

- As agressões físicas e verbais constituem nesse caso os resultados das situações começadas em conflitos. Os alunos como os professores sofrem agressões vindas dum lado como do outro, despoletadas por ameaças.

- O fenómeno bullyng que existe entre alunos é um tipo de conflito desenvolvido que tem repercussões psicológicas no desenvolvimento da criança. Como é um caso muito frequente nas escolas, isso também pode ter repercussões nas relações entre os pais e encarregados da educação e os docentes.Ainda nessa lógica, existe o fenómeno de atribuição de nomes caricatos aos professores resultantes dos conflitos latentes ou abertos constatados entres alunos e professores.

Aqui refere-se, como já dissemos, à uma consequência resultante dos conflitos que pode ser duma maneira supersticiosa, tendo o pensamento virado sobre a possível realização dum acto sobrenatural, fora do controle humano, como também pode ser duma maneira real nas comunidades onde a vida não é considerada no seu verdadeiro valor.

- Ainda, assiste-se um tipo de conflito baseado no rancor e na vingança no seio escolar.

- As insurreições, as revoltas são outros tipos de conflitos constatados na relação daquela comunidade escolar. Obviamente que são situações alimentadas por estímulos próprios cuja reacção corresponde às insurreições ou revoltas que significam não concordar com o tratamento dado.

- Os desafios e os desprezos são formas manifestadas num conflito na obstinação das partes em conflito.

\section{ORIGENS DOS CONFLITOS}

- Aspectos ético-deontológicos

A moral referente a postura que os profissionais observam na realização das tarefas inerentes ao cumprimento cabal do dever profissional tem sido em várias ocasiões negligenciada. Os profissionais da educação naquela escola, muitas vezes pecam sobre esses aspectos que são tão importantes a serem observados, evitando desta maneira os atritos entre elementos da escola ou colisão por não respeito das normas ético-deontológicos.

- Os alunos apontam os aspectos relacionados com o namoro entre alunas e professores ou ainda a pretensão que muitos docentes têm em fazer das suas alunas presas fáceis para satisfazer os seus apetites sexuais tem sido o aspecto que mais conflitos provoca entre docentes e alunas e não só entre docentes e familiares como nesse relato abaixo: 
Aluno 21: “... quando o professor pretender uma menina dentro da sala e essa por sua vez se negar, o professor fica a quedar a aluna na sua disciplina mesmo quando esta estiver a tirar boas notas. (...) Quando a aluna reagir aquilo não tem nenhum efeito porque o professor está acima da aluna. Ele é quem dá aulas e a aluna não tem como reagir ou falar. Esses conflitos levam a que a aluna possa falar muito mal do professor. (...) Este por sua vez, quando se aperceber vai querer atribuir a falta de respeito à aluna porquanto a aluna tem a sua razão."

Os mesmos alunos alegam que alguns aspectos relacionados com a desconfiança que os professores colocam na produção de conhecimentos científicos dos alunos. Por isso, com as melhores notas numa prova, é exigida a sua defesa para merecer a mesma, mas no caso de uma negativa, ninguém é convidado a ressalvar-se da mesma, presumindo que as positivas, são fruto de uma cábula. Nesta desconfiança, revela-se a falta do profissionalismo. Isto explica que o professor ensina para outros fins, como conta o aluno a seguir:

Aluno 29: "O aluno, ao entender bem uma disciplina, tendo as suas positivas e essas não sendo aceites pelo professor presumindo que tivera cabulado..."

O desrespeito que se verifica na aplicação das normas sociais, aceites como sendo o padrão da condução na vida comunitária, revela por parte dos professores a falta da ética e deontologia profissional. Perante algumas situações não abonatórias, o carrancudo aparece defender-se de maneira a pôr em causa a própria moral, no seguinte:

Aluno 5: "Eu the cumprimento na rua e ele não consegue me responder e basta chegar na escola, inventa outras coisas."

Isso, leva a certas observações constatadas pelos alunos na elaboração das provas. Neste exercício, se desprendem de todo profissionalismo querendo avaliar os alunos em matéria não vista, portanto fora dos objectivos da lição para medir a capacidade dos educandos em relação à do professor. Isso fere a própria moral e ética quando se espera resultados positivos com propósitos mal intencionados, como neste caso abaixo:

Aluno 11: "Há professores quando você estiver a fazer provas você não pode olhar de lado nem atrás, não pode falar com ninguém porque se o fizer, vai ouvir só: "sai fora", vem, tira a tua prova. ... porque há alunos bem assimilados e com o aperto dos professores, o aluno não vai fazer bem as provas."

Há casos em que dentro duma turma considerada razoável de 45 alunos que não haja pelo menos uma positiva que possa glorificar os esforços dos alunos. O que se nota, em casos de certos professores, é que aparecem mais negativas do que positivas ou ainda só negativas e não positivas. É de reflectirsobre as práticas dos docentes, embora estando muitos factores em jogo. 
A outra gangrena que enferma os nossos professores naquela escola relaciona-se com a famosa "gasosa" que é a troca de notas contra valores monetários ou contra outros favores.

Aluno 17: "Normalmente, alguns dizem quando estiverem a aplicar a prova, o seguinte: "Na minha casa quero ver cartões de saldo" porque as perguntas que eles aplicam são difíceis. (...) Para todos que vão tirar negativa, eu preciso saldo na minha casa."

Em certos casos não se nota o esforço do aluno que possa garantir o asseguramento da sua formação quando em certos casos a direcção da escola exige uma certa percentagem positiva para considerar uma avaliação de desempenho positivo da parte do docente. Por uma ou por outra razão, alguns acabam por vender em moeda barata a sua própria dignidade de ser um espelho da comunidade.

Algumas situações caricatas resultantes de relações amorosas estabelecidas entre alunas e professores, revelam o nível mais baixo do instinto humano. Essas relações reprováveis a um certo nível de consciência humana e aceitáveis em certas circunstâncias da vida cujas mais vulneráveis ou permissíveis prendem-se com a pobreza e a cultura, desembocam realmente em situações mais desonráveis tais como as gravidezes precoces não assumidas pelos autores provocando dum lado abortos numa sociedade que ainda criminaliza esta prática e de outro, a fuga à responsabilização parental, como se nota aqui:

Aluno 26: "Ele (professor) fazia referência de alguns que não assumem as suas responsabilidades quanto às gravidezes. E eu apanhei-lhe ali porque tinha engravidado uma moça que ele não assumiu. Tiveram que tirar a gravidez. (...) Por ter contrariado o seu pensamento e desvendado esse segredo perante os alunos, então anda chateado comigo todos os dias."

A par disso, esse comportamento indecoroso que certos docentes demonstram perante toda a sociedade não é um bom exemplo a seguir da parte de muitos que esperam do professor que seja um espelho na sociedade.

As tarefas domésticas que os docentes podem fazer, não devem ser atribuídas aos alunos aproveitando a sua condição de superioridade para obrigar aqueles que estiver numa posição inferior a realizar contra a sua vontade acções lucrativas a favor de outrem. Isso se passa um pouco por todas escolas da região que conhecemos, cujos professores tiram proveito da sua posição hierárquica superior em relação aos alunos. Ainda, o caso mais caricato é que alguns dos professores se aproveitam das fraquezas dos alunos para punir os mesmos ao seu benefício. Não achamos bem que os nossos próprios trabalhos caseiros sejam atribuídos a certos "desordeiros" da turma sob pretexto que é uma forma de correcção do comportamento, sobretudo quando são misturados com alguns fortes indícios da corrupção do aluno como no caso a seguir: 
Aluno 21: "Foi um belo dia que cheguei atrasado, (...). Entrei, e o professor mandoume ficar de joelhos e cumpri. Mandou-me levantar. Chamou a menina que chegou junto de mim, fomos a casa dele para acarretar a água enchendo o bidão do quarto de banho. Fi-lo. Pediu-me para cumprir a mesma punição pela segunda vez e cumpri. E a terceira vez pediu-me para comprar um cartão de recarga do telefone no valor de mil kwanzas (equivalentes a 10 dólares americanos) para a menina e deu-me o prazo..."

É assim que muitos se transformam em investigadores de crimes no seio dos alunos assumindo um papel de auxiliar da polícia ao invés de ser educador no seio dos meninos, corrigindo os comportamentos, adequando os hábitos na sociedade, ajudando a colmatar as dificuldades, e em fim, demonstrar a perícia de educar. É desgraça pedir os serviços da polícia quando estiver ao poder do professor um menino com o comportamento um pouco abonatório. Fica incorrecto que a nossa tarefa de educar quando estiver ao nosso poder, sejam utilizados os métodos coercivos para obrigar o aluno a abdicar-se.

Aluno 9: "O professor $X$ sempre ele leva o problema dele da segurança dentro da sala de aula. No ano passado ele perguntou como se curava tradicionalmente o sarampo. Como eu respondi que era através do "limaba" (uma droga), desde ali ele me pegou e me levou à esquadra da polícia queixando-me que faço o uso da droga."

Nessa situação, podemos nos interrogar: o que é que o professor esperava sabendo que o menino é correcto na sua resposta quando o tratamento normal do sarampo tradicionalmente utiliza-se o cannabis, vulgo "limaba"? Essas e outras intenções revelam a falta do profissionalismo e da própria ética.

As situações acima expressas e tantas outras apresentadas pelos alunos são reconhecidas pelos professores e encarregados da educação em que os professores daquela escola pecam na aplicação dos princípios ético-deontológicos. Por isso, na maioria dos casos de conflitos entre os professores, alunos e os familiares sobressaem os aspectos ético-deontológicos que não são devidamente aplicados porque se fossem, evitariam muitos problemas conflituais entre as partes.

Da parte dos professores acrescentam que a falta do sigilo profissional por parte dos colegas tem sido um motivo de muitos conflitos tanto entre os colegas com os pais e encarregados da educação, sobretudo na revelação antecipada dos resultados do conselho de notas, condenando outros colegas para obter favores dos familiares dos alunos, como nessa caso abaixo:

Professor 12: "Porque há determinados colegas, depois do conselho de notas, os colegas avançam até junto das casas dos encarregados da educação, prometendo ao pai e encarregado da educação que não, o aluno tal reprovou, ou aluno tal transitou. Quem fez reprovar o teu filho é o professor tal. Portanto há falta de sigilo profissional." 
Como é do conhecimento de todos podemos compreender que o conjunto de normativos escolares, se desenvolve nos princípios ético-deontológicos para se não desviar de um conjunto de pressupostos susceptíveis de conduzir à acção formativa num rumo certo para o bem de toda a comunidade.

- A Indisciplina e a má educação familiar dos alunos

Partindo da educação familiar, os nossos alunos transportam consigo valores aceites na sociedade, como também alguns comportamentos e atitudes que não coadunam com a sã convivência dos membros da mesma comunidade. E é preciso que os progenitores saibam transferir esses valores caso os tenham. Para além da micro-sociedade que é a família, a comunidade onde vive o aluno tem também alguns valores como alguns comportamentos desviantes que podem ser adoptados tendo em atenção a influência que exercem no seio da comunidade ou na pessoa como indivíduo. Ainda, os aspectos regulamentares em consideração à liberdade do homem, podem causar os conflitos. Nesse caso, os que agem fora das normas estabelecidas, são conotados de indisciplinados. E ninguém na sociedade aceita a indisciplina causada por outrem. Daí que se transforma como uma fonte onde jorra os conflitos. Dentre os diferentes aspectos que os alunos apresentam na produção de situações conflituosas, a indisciplina e a má educação familiar, sãos os aspectos mais relevantes que se verificam como causadores de conflitos na comunidade escolar.

Aluno14: "O mau comportamento que eu demonstrei perante o professor provocou conflitos entre o professor e o meu encarregado da educação. O mau comportamento que eu manifestei perante o professor era não obedecer às ordens dele quando ele quis me cortar o cabelo."

A má educação familiar, quando ela é apresentada como tal torna-se uma situação constrangedora sobretudo por parte daqueles que são os transmissores dessa educação

Aluno23: "Há pais que se acham ofendidos quando dizer que nunca educou bem o seu filho; o seu filho não se comporta bem como que não estivesse nas mãos de um pai."

Essa educação transportada no seio dos outros, as diferentes individualidades não se revêem nas atitudes e comportamentos não aceites pela sociedade e cria atritos por não se conformar com a convivência sadia dos membros. Geralmente, a escola pretende corrigir os mesmos, evitando comportamentos desviantes originários do meio de convivência familiar. Essa educação diferenciada do ponto de vista familiar, é causadora de conflitos na comunidade escolar. O que a escola pretende é moldar uma educação pacífica com um certo padrão para todos. 
Professor 31: "Dependem da educação da própria família. Já foi aqui dito: os alunos geralmente têm tendência de poder criar um pequeno conflito dentro da escola para tirar uma pequena vantagem. O pai que receber a informação, se tiver uma educação bem concebida, porque geralmente a educação da família é herdada, os pais ... se esses pais herdaram uma boa educação dos seus antepassados, portanto ele vai ouvir algo que o filho vai trazer da escola. Ele vai conceber esta situação, este problema, vai analisar e a sua atitude vai na base da sua própria educação."

- A não participação, não acompanhamento e não implicação dos familiares na vida escolar do seu educando.

É de forma unânime que os docentes, alunos e alguns familiares reconhecem que o facto de não acompanhamento dos filhos pelos encarregados da educação, já provocou e continua a provocar atritos entre elementos da comunidade. É preciso que haja entrosamento na acção formativa das novas gerações entre os pais e encarregados da educação e os docentes. Casos muito verificados, são de que os familiares se queixam de falta de tempo material para acompanhar a vida escolar do educando. Para alguns nem sabem o que é preciso para desenvolver os conhecimentos nos alunos, faltando desta feita os materiais escolares necessários porque os pais não foram capazes de adquiri-los para os educandos. O que se verifica ainda, apenas no fim do ano lectivo, estes familiares cobram tanto ao professor como ao discente, querendo desta maneira ter um aproveitamento escolar positivo da parte do seu educando, caso contrário o grande culpado é o professor, como têm hábito de acusar:

Professor13: "Então os nossos encarregados vêm contra nós porque eles só querem ver os seus filhos a transitar. Quando o filho reprova, já cria muitos problemas. $E$ até que sobretudo falarmos das meninas é que o mais preocupante. Das meninas mesmo que ela é tão fraca, fraca mas se reprovar o pai sempre tem a intenção de que o professor andou atrás dela... Então, isso ali tem sido questões que às vezes criam conflitos entre os encarregados e os professores."

Nesse tipo de relação entre a família e a escola, os pais e encarregados da educação, depois do enquadramento do seu educando num estabelecimento de ensino, só espera colher os frutos no final do ano sem os devidos cuidados necessários para uma produção eficaz. Apresentam-se como clientes que deram o seu dinheiro e só esperam receber a mercadoria.

\section{CONCLUSÕES E DISCUSSÃO}

Em guisa de conclusão, podemos ressaltar a existência de três grandes fontes principais que alimentam as contradições e conflitos no processo de ensino-aprendizagem assim como na comunidade escolar em estudo. Tal como encontrado, diferenciação indivi- 
dual dos membros do grupo sugerida por Lee, Huh e Reigeluth (2015), é uma das causas proeminentes vistas nas habilidades sociais dos membros e do próprio grupo. Essas ideias corroboram com os resultados obtidos por Saiti (2014) nas escolas primárias gregas donde as fontes reveladas prendem-se com razões interpessoais e organizacionais, por incompatibilidade de valores, objectivos e opiniões dos membros do grupo como afirma Balay (2006). No nosso caso, o primeiro aspecto relacionado com os docentes prende-se com a falta de aplicação das normas ético-deontológicas no processo docente-educativo. Lamentavelmente, Ulvik, Smith e Helleve (2016), na escola norueguesa, afirmam que muitos dos dilemas profissionais que os professores encontram, têm aspecto ético, tais como nas escolas britânicas referenciadas por Brindley e Bowker (2011), podendo nestes casos, haver situações diferentes. A constatação é que das situações levantadas na escola em estudo, na sua maioria não obedecem às normas estabelecidas para o exercício das funções do professor. Aqui se coloca uma questão. Será que a formação inicial dos professores a nível do país tem obedecido ao conjunto de normas aprovadas pela sociedade sobre a conduta, as competências e habilidades daqueles que são chamados à formação das novas gerações? Esse conjunto de normas definidas tem sido transmitido de forma integral aos futuros professores? Também surge uma outra questão. Dos concursos públicos de ingresso na função professoral, têm tido em conta os aspectos da ética e da deontologia dos professores? Respondidas essas questões, já a escola ou os órgãos que superintendem a acção educativa no Município ou na Província deverão trabalhar para a formação contínua dos professores no que tange a humanização dos serviços educativos. Do conjunto de situações apresentadas pelos elementos da comunidade escolar, a maioria parte desses (namoro com as alunas, assédio sexual, corrupção, trabalhos caseiros, ofensas, maus tratos, etc...), têm um cunho jurídico e podem os seus autores serem responsabilizados criminalmente, o que não acontece numa sociedade habituada a relativizar o crime e a desculpabilizar os criminosos. A responsabilização criminal ajudaria sobremaneira a desencorajar essas práticas indecorosas daqueles que são chamados a serem exemplos na sociedade. Os males constatados não vão de encontro com o que se pretende alcançar para construção de uma sociedade livre de situações constrangedoras na formação integral do homem chamado a uma reflexão constante das suas práticas, a um questionamento reflexivo nos hábitos e costumes adquiridos ao longo dos anos de exercício das funções profissionais.

Com os pais e encarregados da educação, registamos a segunda origem mais produtora de conflitos naquele estabelecimento de ensino. Esta segunda fonte analise as situações provocadas pela falta do acompanhamento dos educandos pelos seus familiares dado que a maioria dos estudos revelam que a implicação dos familiares serve de moderadora à exposição à violência. A relação escola-família é o ponto focal sobre o qual a ajuda mútua deve se desenvolver para uma formação consistente dos alunos. Neste sentido, Kyzar e Jimerson (2018) afirmam que as práticas de engajamento familiar significativas envolvem interacções recíprocas, nos dois sentidos entre educadores e familiares na perspectiva de denúncia e crítica (SÁ, 2004). Apesar das Leis de Bases do Sistema da Educação e Ensino 
(Lei no 10/2001, de 31 de Dezembro e da Lei no 17/16, de 7 de Outubro) legitimarem a participação dos pais e encarregados da educação na vida e gestão escolares, até hoje, os pais só são convidados para actividades com um papel de espectadores, tal como nos recuados anos no sistema português referenciado por Marujo et al. (2005). Os estudos publicados por Silva (2003) dão conta da existência duma correlação forte e positiva entre o aproveitamento escolar, a assiduidade e o comportamento dos alunos assim como a implicação e participação dos familiares na vida escolar dos seus educandos porque Silva (2009, p. 116) completa o seguinte: "quanto mais estreita a relação entre escolas e famílias, maior o sucesso educativo das crianças e jovens." Por não existir este estreitamento de relação, muitas das situações se colocam entre docentes, alunos e familiares, pois, como constata De Sousa e Sacramento (2010), neste comportamento insular, a relação da escola com a comunidade desenvolve-se num registo negativo. O que se verifica é que a falta de tempo e de interesse dos progenitores, acaba por ofuscar o bom relacionamento que deveria existir entre a escola e os familiares, criando os dilemas dum lado como do outro. Algumas situações levantadas pelos elementos da comunidade escolar revelam que a falta de implicação dos pais cria conflitos às vezes intermináveis, tais como:

- Reclamações dos pais quanto a reprovação dos alunos;

- Falta de controlo das ausências dos alunos na escola pelos pais;

- Aplicação de propostas mentirosas;

- A má educação dos pais, transmitida aos educandos;

- A falta de material escolar para o aluno, não adquirido pelos pais;

- Não acompanhamento das tarefas escolares para casa;

Essas e outras situações atinentes aos familiares, são agravadas pelo nível cultural dos progenitores ou encarregados da educação, pelo facto de não ter a capacidade intelectual de interpretar os fenómenos e as situações que se apresentam na escola, assumindo a postura de queixoso e não de culpado.

A terceira origem dos conflitos constatada e atribuída aos alunos dá conta da indisciplina e má educação familiar dos alunos. Como revelam Duarte, Escario e Sanagustín (2017), as atitudes dos jovens surgem duma intensa interacção com os grupos sociais de referência. Daí a importância da influência da família, as características da escola e as interacções sobre as atitudes em relação ao meio ambiente. Tal como considerado por Munhaes e Novaes (2017), a indisciplina contribui para a evasão escolar, pela pressão para que o aluno se evada, tornou-se um problema a larga escala (KESUI, MANDUKU, \& SANG, 2017). Munhaes e Novaes (2017) concluem dizendo que a existência de conflitos escolares, é uma demonstração que os estudantes estão reagindo às imposições, já que a disciplina reverte-se ao respeito ou obediência às regras impostas (DA SILVA, NEGREIROS, \& ALBANO, 2017). Todas as sociedades, sendo elas primitivas como modernas são guiadas por um conjunto de normas dentro das quais todos os elementos se conformam. $\mathrm{E}$ a indisciplina aparece quando alguém sapa as regras de convivência, as normas estabelecidas. É o caso de muitos alunos não querer se conformar com o estabelecido, agindo a margem 
dele. Isto também é fruto de uma educação recebida no seio familiar que, como sabemos é diferenciada de uma família à outra ou de um meio ao outro. Cada um é produto do ambiente no qual se desenvolve. Nos trabalhos de Labella e Masten (2018), é reconhecido que as crianças de família com certos problemas são propensas de desenvolver a agressividade nas escolas, o que presume a má educação recebida naquela família porque como reconhecem Zhou e Jiang (2017), o impacto dessa educação familiar pode durar a vida toda. É assim que as situações apresentadas relativas ao desrespeito das normas de convivência ou dos regulamentos escolares, as ofensas, a não realização das tarefas escolares, o bullyng e cyberbullyng, etc... apontam para a indisciplina e má educação dos alunos.

Dessas todas fontes e situações, como constatamos, levaram a um conjunto de conflitos que foram definidos pelos próprios elementos da escola, a saber: as agressões físicas e verbais, as vinganças, o rancor, o ódio, o bullyng, as insurreições, as revoltas, os desafios e desprezos, etc... que na maioria das vezes se manifestam entre alunos e professores, com uma transposição aos pais e encarregados da educação, móbil de escaramuças entre estes e os docentes.

\section{LIMITAÇÕES DO ESTUDO E INVESTIGAÇÕES FUTURAS}

O estudo levado acabo numa escola do I ciclo cujos resultados não podem ser generalizados por ser um estudo de caso, as suas conclusões dependem intrinsecamente das condições inerentes ao ambiente escolar em estudo particularizando o contexto da realização do mesmo. Neste caso, abre-se logo uma oportunidade para continuar com a mesma investigação nas escolas da região com vista a generalizar as conclusões que poderão ser alcançadas. Ainda, pode existir um estudo comparativo com outras escolas de outros níveis, da mesma região ou ainda do mesmo país para que os resultados obtidos fossem comparados com outros países.

Por outro, os resultados obtidos numa amostra intencional tal como neste caso, para além de ser constituída por indivíduos que já tiverem casos semelhantes, não dá a voz àqueles que assistiram de longe o desenrolar da cena para a emissão do seu ponto de vista julgado imparcial.

A outra limitação que julgamos de realce, refere-se às principais componentes da comunidade escolar (professores, alunos e familiares dos alunos), e o estudo não apontou o pessoal administrativo e auxiliar da escola que pode também ter o seu ponto de vista, por existir uma acção coordenada para o funcionamento da escola. Para além de alguns casos generalizados nos três subgrupos (professores, alunos e pais e encarregados da educação), houve acusações uns contra outros. Desta forma, é recomendável que noutros estudos do género, outras vozes se juntam para termos os pontos de vistas diferentes com uma variada gama dos instrumentos para recolha de mais dados específicos que possam ser analisados para confirmar ou infirmar os nossos dados e conclusões. 
Todavia, acreditamos que o nosso estudo fornece resultados significativos para continuar contribuindo na pesquisa sobre os conflitos escolares de modos a trabalhar na prevenção dos mesmos e na sua resolução plausível com vista a alcançar efeitos positivos. Faria também questão de futuras investigações a questão que se prende com a formação ético-deontológica dos professores por quanto a disciplina que é de Formação Pessoal, Social e Deontológica não der grandes efeitos esperados. 


\section{REFERÊNCIAS}

ANGOLA. Lei n 10/2001, de 31 de Dezembro, Lei de Bases do Sistema Educativo Angolano.

ANGOLA. Lei n 17/16, de 07 de Outubro, Nova Lei de Bases do Sistema Educativo Angolano.

BAGNALL, Richard G.; NAKAR, Sonal. A critical reflection of codes of conduction vocational education. Journal of Moral Education, Bermingham, v.47, n. 1, p. 78 - 90, out. 2017. Disponível em: <https://doi.org/10.1080/03057240.2017.1379964>. Acesso em: 10 jul. 2018.

BALAY, Reflik. Conflict management strategies of administrators and teachers. Asian Journal of Management Cases, Pakistan,v. 3, n.1, p. 5 - 24, mar. 2006.

BENDERSKY, Corinne; HAYS, Nicholas A. The positive effects of status conflicts in teams where membres perceive status hierarchies differently. Social Psychological and Personality Science, East Lansing, v.8, n. 2, p.124 - 132,mar. 2017.

BRINDLEY, Sue; BOWKER, Anne. Towards na understanding of the place of ethics in school-based action research in the United Kingdom. Education Action Research, Londres, v. 21, n. 3, p. 289 - 306, set. 2013. Disponível em: <https://doi.org/10.1080/09650792.203.815037>. Acesso em: 07 jan. 2018.

CARTON, Andrew M.; TEWFIK, Basima A. Perspective -A new look at conflict management in work groups. Organization Science, Pennsylvania, v. 27, p.1125-1141, out. 2016.

CHEN, Gilad et al. Teams as innovative systems: Multilevel motivational antecedents of innovation in R \& D teams. Journal of Applied Psychology, Maryland, v. 98, n. 6,p. 1018-1027, abr. 2013.

CHENG, Jocy T.; TRACY, Jessica L.; HENRICH, Joseph. Pride, personality, and the evolutionary foundations of human social status. Evolution and Human Behavior, Washington, v. 31, n. 5, p. 334 - 347, fev. 2010. Disponível em: http://dx.doi.org/10.1016/j.evolhumbehav.2010.02.004. Acesso em: 10 jul. 2018.

DA SILVA, Algeless Milka Pereira Meireles; NEGREIROS, Fauston; ALBANO, Ronaldo Matos. Indiscipline at the public school: teachers'conceptions on causes and intervention. International Journal of Research in Educationand Science, Piaui, v. 3, n.1, p. 1 - 10,Winter 2017.

DE SOUSA, Maria Martins; SARMENTO, Teresa. Escola - Família - Comunidade: Uma relação para um sucesso educativo. Gestão e Desenvolvimento, Lisboa v.17, n.18, p. 141 - 156 jun. 2009-2010. DOGAN, Soner. Conflicts management model in school: a mixed design study. Journal of Education and Learning, Sivas, v. 5, n. 2, p. $200-219$, mar. 2016.

DUARTE, Rosa; ESCARIO, José Julián; SANAGUSTíN, María-Vitoria. The influence of the family, the school, and the group on the environmental attitudes of European students. Environmental Education Research, Zaragoza,v. 23, n. 1, p. 23 - 42, ago. 2017. Disponível em: <https://doi.org/1 0.1080/13504622.2015.1074660>. Acesso em: 02 mar 2018.

GÖKSOY, Süleyman; ARGON, Türkan. Conflicts at school and their impact on teachers. Journal of Educationand Training Studies, Beaverton, v. 4, n. 4, p. 197 - 205, abr. 2016. 
GROYSBERG, Boris; POLZER, Jeffrey T; ELFENBEIN, Hillary Anegr. Too many cooks spoil the broth: How high-status individuals decrease group effectiveness. Organization Science, Boston, v. 22, n. 3, p. $722-737$, jun. 2011.

HOJBOTA, Ana-Maria: BUTNARU, Simona; ROTARU, Carmen; TITA, Silviu. Facing conflicts and violence in schools - a proposal for a new occupation: the mediation counsellor. Procedia - Social and Behavioral Sciences, Bled, v. 142, p. 396 - 402,ago. 2014.

HYMEL, Shelley; SWEAR, Susan M. Four decades of research on school bullying: A introduction. American Psychologist, Los Angeles, v. 70, n. 4,p. 293 - 299, jun. 2015. Disponível em:http://dx. doi.org/10.1037/a0038928. Acesso em: 10 jul. 2018.

KESUI, Hellen Chelagat; MANDUKU, Joshua; SANG, Hellen. Effectiveness of guidance and counselling programs in managing indiscipline cases in secondary schools in Bureti Sub-County, Kericho County, Kenya. European Jounal of Education Studies, Bucharest, v.3, n.10, p. 762 - 774, mar.2017.

$\mathrm{KOH}$, Jun-Bin; WONG, Jennifer. S. Survival of the fittest and the sexiest: Evolutionary origins of adolescent bullying. Jounal of Interpersonal Violence, British Columbia, v. 32, n.17, p. 2668 - 2690, set. 2017.

KYZAR, Kathlenn; JIMERSON, Jo Beth. Bridging the school - home divide in the middle grades: A process for strength ening school - family partnerships. Middle School Journal, Texas, v. 49, n. 1, p. 13 - 23, jan. 2018. Disponível em: <https://doi.org/10.1080/00940771.2018.1399331>. Acesso em: 10 jan. 2018.

LABELLA, Madelyn H.;MASTEN, Ann S. Family influence on the development of aggression and violence. Current Opinion in Psychology, East River Parkway, v. 19, p. 11 - 16, fev. 2018. Disponível em: <http://dx.doi.org/10.1016/j.copsyc.2017.03.028>. Acesso em: 20 fev. 2018.

LEE, Dabae; HUH, Yeol; REIGELUTH, Charles M. Collaboration, intragroup conflict, and social skills in Project-based learning. Instructional Science, New York, v. 43, n. 5, p. 561 - 590, set. 2015.

LEE, Hun Whee; CHOI, Jin Nam; KIM, Seongsu. Does gender diversity help teams constructively manage status conflict? An evolutionary perspective of status conflict, team psychological safety, and team creativity. Organizational Behavior and Human Decision Processes, East Lansing, v.144, p. 187 - 199, jan. 2018.

LU, Minjie; FUNG, Helene H.; DOOSJE, Bertjan. Intergroup conflicts: When interdependent individuals feelless dialectical than independent individuals. Personality and Individual Differences, Amsterdão, v. 105, p. 150 - 157, jan. 2017. Disponível em: <https://doi.org/10.1016/j.paid.2016.09.027>. Acesso em: 11 set. 2017.

MARUJO, Helena Águeda; NETO, Luís Miguel Afonso Neto; PERLOIRO, Mária de Fátima A família e o sucesso escolar. $4^{\mathrm{a}}$ ed. Lisboa: Edições Científica Editorial Presença, 2005.

MILES, Matthew. B.; HUBERMAN, A. Michael. Qualitative data analysis. 2nd Ed. Thousand Oaks, California: Sage Publications, 1994. 
MUNHAES, Cristina; NOVAES, Adelina. Indisciplina: Representações sociais de uma comunidade escolar da cidade de São Paulo. Revista Ambiente Educação, São Paulo, v. 10, n. 1, p. 117 - 145, jun. 2017.

NAIRZ-WIRTH, Erna., \& FELDMANN, Klaus. Teachers'views on the impact of teacher - student relationships on school. Pedagogy, Culture \& Society, Vienna, v. 25, n. 1,p. 121 - 136, set. 2016. Disponível em: <https://doi.org/10.1080/14681366.2016.1230881>. Acesso em: 12 set. 2017.

OMISORE, B. O., \& ABIODUN, A. R. Organizational conflicts: causes, effects and remedies. International Journal of Academic Research in Economics and Management Sciences, Abeokuta, v. 3, n. 6 , p. $118-137$, dez. 2014.

OZGAN, Habib. The usage of domination strategies in conflicts between the teachers and students: a case study. Educational Resaerch and Reviews, Gaziante, v.11, n. 4, p. 146 - 152, fev. 2016.

PETTIT, NathanC.; DOYLE, Sarah P.; LOUNT, Robert B.; TO, Christopher. Cheating to get ahead or to avoid falling behind? The effect of potential negative versus positive status change on unethical behavior. Organizational Behavior and Human Decision Processes, Columbus, v.137, p. 172 183,nov. 2016.

SÁ, Virgino. A participação dos pais na escola pública portuguesa. Uma abordagem sociológica e organizacional. Braga: Universidade do Ninho, 2004.

SAITI, Anna. Conflicts in schools, conflict management styles and the role of the school leader. A study of Greek primary school educators. Educational Management Administration \& Leadership, Athens, v. 43, n. 4, p. $582-609$, jun. 2014.

SERVOSS, Timothy J. School security and student misbehavior. A multi-level examination. Youth \& Society, Buffalo, v. 49, n. 6, p. 755 - 778, set. 2017. Disponível em: <https://doi.org/10.1177/0044118X14561007>. Acesso em: 15 jul. 2018.

SHAHMOHAMMADI, N. Conflict management among secondary school students. Procedia-Social and Behavioral Sciences, Teerão, v.159, n. 23, p. 630 - 635, dez. 2014.

SILVA, P. Escola - Família uma relação armadilhada: Interculturalidade e relações de poder. Porto: Edições Afrontamento, 2003, 412 p.

SILVA, P. O contributo da escola para a actividade parental, numa perspectiva de cidadania. In: CONSELHO NACIONAL DE EDUCAÇÃO, 2009. Lisboa. Actas de seminário... Lisboa: CNE, 2009.

TITREK, Osman.; MIIARAL, Muammer.; KIZILKAYA, Deniz Barut. Investigating primary school teachers'perception of conflict management strategies used by principals. Journal of Human Sciences, Sakarya, v.12, n.2, p. $1735-1755$, out. 2015.

ULVIK, Marit;, SMITH, Kari; HELLEVE, Ingrid. Ethical aspects of Professional dilemmas in the first year of teaching. Professional Development in Education, Bergen, v. 43, n.2,p. 236 - 252, mai. 2016. Disponível em: <https://doi.org/10.1080/19415257.2016.1178163>. Acesso em: 15 jul. 2018.

VASQUEZ-SALGADO, Yolanda; GREENFIELD, Patricia M.; BURGOS-CIENFUEGOS, Rocio. Exploring Home-School value conflicts: Implications for academic achiements and well-being among 
latino first-geberation college students. Journal of Adolescent Research, Los Angeles, v. 30, n. 3, p. 271- 305, mai. 2015. Disponível em: <https://doi.org/10.1177/0743558414561297>. Acesso em: 08 de jul. 2018.

WHITESIDE, Racheal. Peer mediation as viable option for school conflict resolution programs. Undergraduate Journal of Service Learning and Community-Based Research, Buffalo, v.5, p. 1 - 10, fev. 2016.

ZHOU, Fang., \& JIANG, Tao. A discussion of and suggestions to the problems in Chinese family education. Creative Education, Nanchang, v. 8, n. 3, p. 347 - 358, mar. 2017. Disponível em:<https:// doi.org/10.4236/ce.2017.83027>. Acesso em: 10 jan. 2018. 